\title{
A longitudinal study of the relationship between receptivity to e-cigarette advertisements and e-cigarette use among baseline non-users of cigarettes and e-cigarettes, United States
}

\author{
Israel T. Agaku ${ }^{*}$, Kevin Davis², Deesha Patel' ${ }^{1}$ Paul Shafer ${ }^{2}$, Shanna Cox ${ }^{1}$, William Ridgeway ${ }^{2}$ and Brian A. King ${ }^{1}$
}

\begin{abstract}
Background: We investigated the relationship between receptivity to electronic cigarette (e-cigarette) advertisements at baseline and e-cigarette use at follow-up among adult baseline non-users of cigarettes and e-cigarettes.

Methods: A nationally representative online panel was used to survey non-users of cigarettes and e-cigarettes ( $n=2191)$ at baseline and 5-month follow-up. At baseline, respondents were shown an e-cigarette advertisement and asked if they were aware of it (exposure). Among those exposed, receptivity was self-rated for each ad using a validated scale of 1 to 5 for agreement with each of six items: "worth remembering," "grabbed my attention," "powerful," "informative," "meaningful," and "convincing." Logistic regression was used to measure the relationship between receptivity at baseline and e-cigarette use at follow-up.

Results: Among baseline non-users of cigarettes and e-cigarettes, 16.6\% reported exposure to e-cigarette advertisements at baseline; overall mean receptivity score was 2.77. Among baseline non-users who reported exposure to e-cigarette advertisements, incidence of e-cigarette use at follow-up was 2.7\%; among baseline nonusers who reported not being exposed to e-cigarette advertisements, incidence of e-cigarette use at follow-up was 1.3\%. The attributable risk percentage for e-cigarette initiation from e-cigarette advertisement exposure was 59.3\%; the population attributable risk percentage from e-cigarette advertisement exposure was $22.6 \%$. Receptivity at baseline was associated with e-cigarette use at follow-up ( $\mathrm{aOR}=1.57 ; 95 \% \mathrm{Cl}=1.04-2.37$ ).

Conclusions: Receptivity to e-cigarette advertisements at baseline was associated with greater odds of e-cigarette use at follow-up among baseline non-users of cigarettes and e-cigarettes. Understanding the role of advertising in e-cigarette initiation could help inform public health policy.
\end{abstract}

Keywords: E-cigarettes, Advertisements, Tobacco control, Policy, Receptivity, Initiation

\footnotetext{
* Correspondence: wgn9@cdc.gov; iagaku@cdc.gov

${ }^{1}$ Office on Smoking and Health, National Center for Chronic Disease Prevention and Health Promotion, Centers for Disease Control and Prevention, 4770 Buford Hwy NE, Mailstop F-79, Atlanta, GA 30341, USA Full list of author information is available at the end of the article
} 


\section{Background}

Electronic cigarette (e-cigarette) advertising expenditures in the United States increased approximately 18-fold from 2011 (\$6.4 million) to 2014 (\$115 million) [1, 2]. Correspondingly, U.S. e-cigarette sales have increased rapidly in recent years, reaching $\$ 2.5$ billion in 2014 [3, 4]. Some e-cigarette advertisements have included claims of relative advantages of e-cigarettes over conventional cigarettes, including that e-cigarettes are healthier, more socially acceptable, or could be used to quit conventional cigarette smoking $[5,6]$. An estimated $58.4 \%$ of current cigarette smokers who use e-cigarettes report doing so to quit conventional cigarette smoking [7], despite inconclusive evidence on the efficacy of e-cigarettes for long-term cessation [8].

Several cross-sectional studies have demonstrated an association between e-cigarette advertisement exposure and actual or intended e-cigarette use among adults $[6,9,10]$. However, these cross-sectional studies are limited by the inability to establish temporality between exposure and outcome. Further information on the impact of e-cigarette advertising exposure on use could help inform regulatory efforts to prevent e-cigarette initiation and established use, especially among youth and young adults [11, 12]. Therefore, this longitudinal study investigated the relationship between receptivity to e-cigarette advertisements and current e-cigarette use among a national sample of U.S. adults who were baseline non-users of conventional cigarettes and e-cigarettes.

\section{Methods}

Data

We used data from a nationally representative longitudinal online survey of US adults aged $\geq 18$ years administered by GfK Custom Research. Participants were recruited from a probability sample of residential postal addresses covering approximately $95 \%$ of all U.S. households. Invitation letters were mailed to all sampled households and contained website links and passwords to enable the selected household to access the survey. The probability of selection was known for all participants and participants could not volunteer for study enrollment. Those who were not Internet-enabled were provided additional study incentive payments to complete the survey in public locations with Internet access, such as libraries.

The survey was conducted in two waves: April 12 to June 30, 2014 (baseline) and September 11 to November 17, 2014 (follow-up). Non cigarette smokers were defined as respondents who never smoked or who reported smoking at least 100 cigarettes in their lifetime, but smoked "not at all" at baseline. Non e-cigarette users were persons who reported that they used e-cigarettes "not at all" at baseline. All baseline non users of cigarettes or e-cigarettes who participated at baseline ( $n=3123)$ were re-contacted for follow-up approximately 5 months later; a longitudinal retention rate of $74.6 \%$ was achieved. All analyses reported in this study are based on the longitudinal cohort of $n=2191$ persons who neither smoked cigarettes nor used e-cigarettes at baseline and who completed both survey waves.

\section{Measures}

Exposure to e-cigarette advertisements at baseline

To measure exposure to e-cigarette advertisements, respondents were shown one of 5 popular e-cigarette advertisements (three Blu and two Njoy advertisements) at random via a video stream within the survey. Those unable to view the video stream were shown a storyboard of images from the advertisement. Using this protocol to cue recall, participants were then asked to indicate whether they had seen the e-cigarette advertisement on either television or online in the past 3 months. Respondents who reported having seen an advertisement in the past 3 months were defined as having being exposed to the e-cigarette advertisement they viewed.

\section{Receptivity to e-cigarette advertisements at baseline}

Receptivity to e-cigarette advertisements among those who reported being exposed was measured with a multiitem scale similar to those used in previous research [13]. After viewing each advertisement in the survey, each respondent was asked whether he or she agreed or disagreed with the following statements: (1) "this ad was worth remembering"; (2) "this ad grabbed my attention"; (3) "this ad was powerful"; (4) "this ad was informative"; (5) "this ad was meaningful"; and (6) "this ad was convincing". Each item was assessed on a scale from 1 (strongly disagree) to 5 (strongly agree). Item-specific responses were averaged for each advertisement, and then averaged across advertisements, to obtain a single value (range $1-5$ ).

\section{Smoking history and awareness of tips advertisements}

Cigarette smoking history of baseline non-users of cigarettes and e-cigarettes was explored using a lifetime threshold of 100 cigarettes; respondents were classified as never smokers (smoked $<100$ cigarettes in lifetime) or former smokers (smoked $\geq 100$ cigarettes in a lifetime but were not smokers at the time of the survey).

The 2014 wave of the Centers for Disease Control and Prevention's national tobacco education campaign Tips From Former Smokers (Tips) aired in two 9-week phases that overlapped with the study period (Phase 1: February 3-April 6, 2014; Phase 2: July 7-September 7, 2014) [14]. Therefore, we assessed exposure to Tips advertisements ("yes" or "no") as a potential confounder. 


\section{Current e-cigarette use at follow-up}

Current e-cigarette use at follow-up was defined as using e-cigarettes "some days" or "every day" (vs. "not at all").

\section{Statistical analysis}

Subgroup differences in exposure and receptivity were assessed using $\mathrm{X} 2$ and Wald tests. Based on prevalence of e-cigarette use at Wave 2 by advertisement exposure at Wave 1 among baseline non-users of cigarettes and e-cigarettes, we estimated the attributable risk percentage (among those exposed) and the population attributable risk percentage (among the entire population).

Multivariable logistic regression was used to measure the association between receptivity to e-cigarette advertisements and e-cigarette use at follow-up among baseline non-users of cigarettes and e-cigarettes, controlling for sex, age, race/ethnicity, awareness of Tips advertisements, cigarette smoking history, educational attainment, and presence of a smoker in the household. We controlled for regional variation in e-cigarette consumption by including region fixed effects. Data were weighted, and corresponding population totals were calculated for select estimates; statistical significance was ascertained using a threshold of $p<0.05$.

\section{Results}

Table 1 summarizes characteristics of study participants at baseline. A majority of respondents were non-Hispanic white $(69.4 \%)$, male $(52.4 \%)$, and ages 25 to $64(68.8 \%)$. About one-third (34.5\%) had attained at least a college degree, and over two-third (68.9\%) were never smokers.

\section{Exposure to E-cigarette advertisements at baseline}

Overall, 16.6\% of nonsmoking U.S. adults (33.9 million) were exposed to an e-cigarette advertisement at baseline. By race/ethnicity, prevalence of self-reported exposure to an e-cigarette advertisement was highest among nonHispanic blacks (28.1\%) and lowest among non-Hispanic whites $(14.5 \% ; p=0.009)$. By education, prevalence of exposure was highest among those with less than a high school education $(22.2 \%)$ and lowest among those with at least a college degree $(12.3 \% ; p=0.002)$. Prevalence was significantly higher among those who lived with a smoker in the household (25.4\%) compared to those who did not (15.5\%). No significant differences in e-cigarette advertisement exposure was observed by age or sex (see Table 1).

\section{Receptivity to E-cigarette advertisements at baseline}

The overall mean receptivity score among baseline nonusers was 2.77. By age, the mean score was highest among those aged 18-24 years (2.88) and lowest among those aged $25-44$ years $(2.67)(p=0.027)$. By race/ethnicity, mean receptivity scores were highest among those classified as 'other, non-Hispanic' (3.15) and lowest among non-Hispanic whites $(2.68)(p<0.0001)$. By education level, mean receptivity scores were highest among those with less than a high school education (3.23) and lowest among those with at least a college degree (2.58) $(p<0.0001)$. No significant gender differences were noted for receptivity to e-cigarette advertisements.

\section{Incidence and determinants of current E-cigarette use at follow-up}

Among all baseline non-users of cigarettes and e-cigarettes, $1.3 \%$ (2.7 million persons) reported current e-cigarette use at follow-up (Table 2). Among baseline non-users who reported exposure to an e-cigarette advertisement at baseline, $2.7 \%$ reported e-cigarette use at follow-up; among baseline non-users who reported not being exposed to an ecigarette advertisement at baseline, $1.1 \%$ reported ecigarette use at follow-up. In relation to e-cigarette initiation, the attributable risk percentage due to e-cigarette advertisement exposure was $59.3 \%$, and the population attributable risk percentage was $22.6 \%$.

Demographic differences in incidence of e-cigarette use among baseline non-users of cigarettes and e-cigarettes were observed. By race/ethnicity, incidence was highest among non-Hispanic whites $(1.6 \%)$ and lowest among nonHispanic blacks $(0.3 \%)(p=0.029)$. By education, incidence was highest among those with only a high school education (2.1\%) and lowest among those with a college degree or higher $(0.3 \%)(p=0.004)$. Incidence of e-cigarette use at follow-up also varied significantly by smoking history and presence of another smoker in the household. The followup incidence among former smokers was $2.5 \%$ compared with $0.8 \%$ among never smokers $(p=0.011)$. By household smoking, incidence was $0.7 \%$ at follow-up among those with no smoker in the household and 6.1\% among those with a smoker in the household $(p=0.004)$. No significant differences were noted by age or sex.

Receptivity to e-cigarette advertisements at baseline among non-users of cigarettes and e-cigarettes was significantly associated with e-cigarette use at follow-up $(\mathrm{aOR}=1.57 ; 95 \% \mathrm{CI}=1.04-2.37)$ (Table 3). Among baseline non-users, the odds of e-cigarette uptake at follow-up were lower among males than females $(\mathrm{aOR}=0.35 ; 95 \% \mathrm{CI}=0.14-0.90)$. Former smoking $(\mathrm{aOR}=4.30 ; 95 \% \mathrm{CI}=1.47-12.61)$ and presence of another smoker in the household $(\mathrm{aOR}=6.48 ; 95 \%$ $\mathrm{CI}=2.47-16.97)$ predicted e-cigarette use at follow-up. Baseline age, awareness of Tips advertisements, race/ethnicity, and education were not significantly associated with e-cigarette use at follow-up.

\section{Discussion}

Approximately 1 in 6 U.S. adults who did not smoke conventional cigarettes reported exposure to an e- 
Table 1 Baseline Exposure ${ }^{a}$ and Receptivity ${ }^{b}$ to E-cigarette Advertisements and E-Cigarette Use ${ }^{c}$ at Follow-Up among Baseline Nonusers of Cigarettes and E-cigarettes $(n=2191)$

\begin{tabular}{|c|c|c|c|c|c|c|c|}
\hline \multirow[b]{2}{*}{ Demographic variable } & \multicolumn{2}{|c|}{ Distribution } & \multicolumn{3}{|c|}{ Exposure $^{a}$ to E-cigarette Advertisements at Baseline } & \multicolumn{2}{|c|}{$\begin{array}{l}\text { Mean Receptivity to E-cigarette } \\
\text { Advertisements at Baseline }\end{array}$} \\
\hline & $\%$ & $\mathrm{~N}$ & $\begin{array}{l}\text { Prevalence } \\
{[95 \% \mathrm{Cl}]}\end{array}$ & $\begin{array}{l}P \text {-Value } \\
\text { (X2 test) }\end{array}$ & $\begin{array}{l}\text { Weighted Population Count } \\
{[95 \% \mathrm{Cl}] \text {, millions }}\end{array}$ & Mean Scale Score $[95 \% \mathrm{Cl}]$ & $\begin{array}{l}\text { P-Value } \\
\text { (ANOVA) }\end{array}$ \\
\hline All nonsmokers & 100.0 & 2191 & $16.6(14.7-18.5)$ & - & $33,914,032$ & $2.77(2.72-2.83)$ & - \\
\hline \multicolumn{8}{|l|}{ Age, years } \\
\hline $18-24$ & 11.3 & 264 & $11.4(6.2-16.7)$ & 0.241 & $2,639,467$ & $2.88(2.71-3.05)$ & 0.027 \\
\hline $25-44$ & 33.3 & 776 & $17.4(13.9-21)$ & & $11,854,580$ & $2.67(2.58-2.76)$ & \\
\hline $45-64$ & 35.5 & 828 & $17.2(14.1-20.4)$ & & $12,483,029$ & $2.79(2.7-2.87)$ & \\
\hline $65+$ & 19.8 & 462 & $17.2(13.1-21.2)$ & & $6,937,030$ & $2.86(2.76-2.96)$ & \\
\hline \multicolumn{8}{|l|}{ Sex } \\
\hline Male & 52.4 & 1221 & $15.6(13-18.1)$ & 0.265 & $16,658,131$ & $2.77(2.7-2.84)$ & 0.849 \\
\hline Female & 47.6 & 1110 & $17.8(14.9-20.6)$ & & $17,256,086$ & $2.78(2.7-2.85)$ & \\
\hline \multicolumn{8}{|l|}{ Race/ethnicity } \\
\hline White, non-Hispanic & 69.4 & 1617 & $14.5(12.6-16.5)$ & 0.009 & $20,577,407$ & $2.68(2.63-2.73)$ & $<0.001$ \\
\hline Black, non-Hispanic & 10.3 & 239 & $28.1(20.1-36.1)$ & & $5,880,073$ & $3.01(2.81-3.21)$ & \\
\hline Hispanic & 7.1 & 166 & $16.3(8.3-24.3)$ & & $2,374,098$ & $2.69(2.49-2.88)$ & \\
\hline Other, non-Hispanic & 13.3 & 309 & $18.8(12.2-25.4)$ & & $5,086,565$ & $3.15(2.96-3.34)$ & \\
\hline \multicolumn{8}{|l|}{ Education } \\
\hline$<$ High school & 9.5 & 221 & $22.2(13.9-30.4)$ & 0.002 & $4,293,227$ & $3.23(3.01-3.44)$ & $<0.001$ \\
\hline High school & 26.8 & 624 & $16.6(12.8-20.5)$ & & $9,078,229$ & $2.86(2.75-2.97)$ & \\
\hline Some college & 29.3 & 683 & $19.9(16.3-23.6)$ & & $11,909,948$ & $2.77(2.69-2.86)$ & \\
\hline$\geq$ College degree & 34.5 & 803 & $12.3(9.8-14.8)$ & & $8,633,227$ & $2.58(2.51-2.65)$ & \\
\hline \multicolumn{8}{|l|}{ Cigarette smoking history } \\
\hline Never smokers & 68.9 & 1605 & $16.0(13.6-18.3)$ & 0.301 & $22,418,717$ & $2.8(2.73-2.86)$ & 0.170 \\
\hline Former smokers & 31.1 & 726 & $18.1(14.8-21.4)$ & & $11,495,304$ & $2.72(2.64-2.81)$ & \\
\hline \multicolumn{8}{|l|}{ Household smoking } \\
\hline No smoker in household & 88.6 & 2064 & $15.5(13.5-17.4)$ & 0.006 & $27,946,577$ & $2.76(2.70-2.81)$ & 0.118 \\
\hline Smoker in household & 11.4 & 267 & $25.4(18.6-32.1)$ & & $5,924,750$ & $2.9(2.73-3.08)$ & \\
\hline
\end{tabular}

Abbreviations: $\mathrm{Cl}$ confidence interval, e-cigarette Electronic cigarette

${ }^{a}$ Exposure, a binary variable (yes or no) was assessed at baseline by showing respondents an e-cigarette advertisement selected randomly from 5 popular TV and online advertisements and asking if they were aware of it

${ }^{\mathrm{b}}$ Receptivity was computed as an average of six items, each item self-rated on a scale from 1 (strongly disagree) to 5 (strongly agree) describing the perceived effectiveness of the advertisement shown to the respondent. The six items measured in relation to the advertisement's effectiveness were "worth remembering," "grabbed my attention," "powerful," "informative," "meaningful," or "convincing." Responses were averaged for each ad and then across advertisements to obtain a single value for a respondents' overall receptivity of the e-cigarette advertisements

${ }^{c}$ Current e-cigarette users at follow-up were defined as persons who reported using e-cigarettes some days or every day

cigarette advertisement at baseline. Among baseline non-users of cigarettes and e-cigarettes, receptivity to e-cigarette advertisements at baseline was associated with higher odds of using e-cigarettes at follow-up. These findings suggest that the responsible regulation of e-cigarette advertising targeted at vulnerable populations may be warranted to minimize potential public health harms. For example, restrictions can be placed on media where e-cigarettes can be advertised in an effort to prevent e-cigarette initiation and established use among susceptible populations, particularly youth and nonsmoking adults. To better monitor tobacco marketing activities over time, e-cigarette companies could also be required to report to the Federal Trade Commission their annual advertising and promotional expenditures, overall and by advertising channel, as is currently required for cigarettes and smokeless tobacco products $[15,16]$.

In May 2016, the U.S. Food and Drug Administration finalized a rule extending its authority to all tobacco products, including e-cigarettes and enables future rulemaking regarding tobacco product manufacturing, marketing, and sales [17]. Given the rapidly evolving and expanding e-cigarette market, efforts are also warranted 


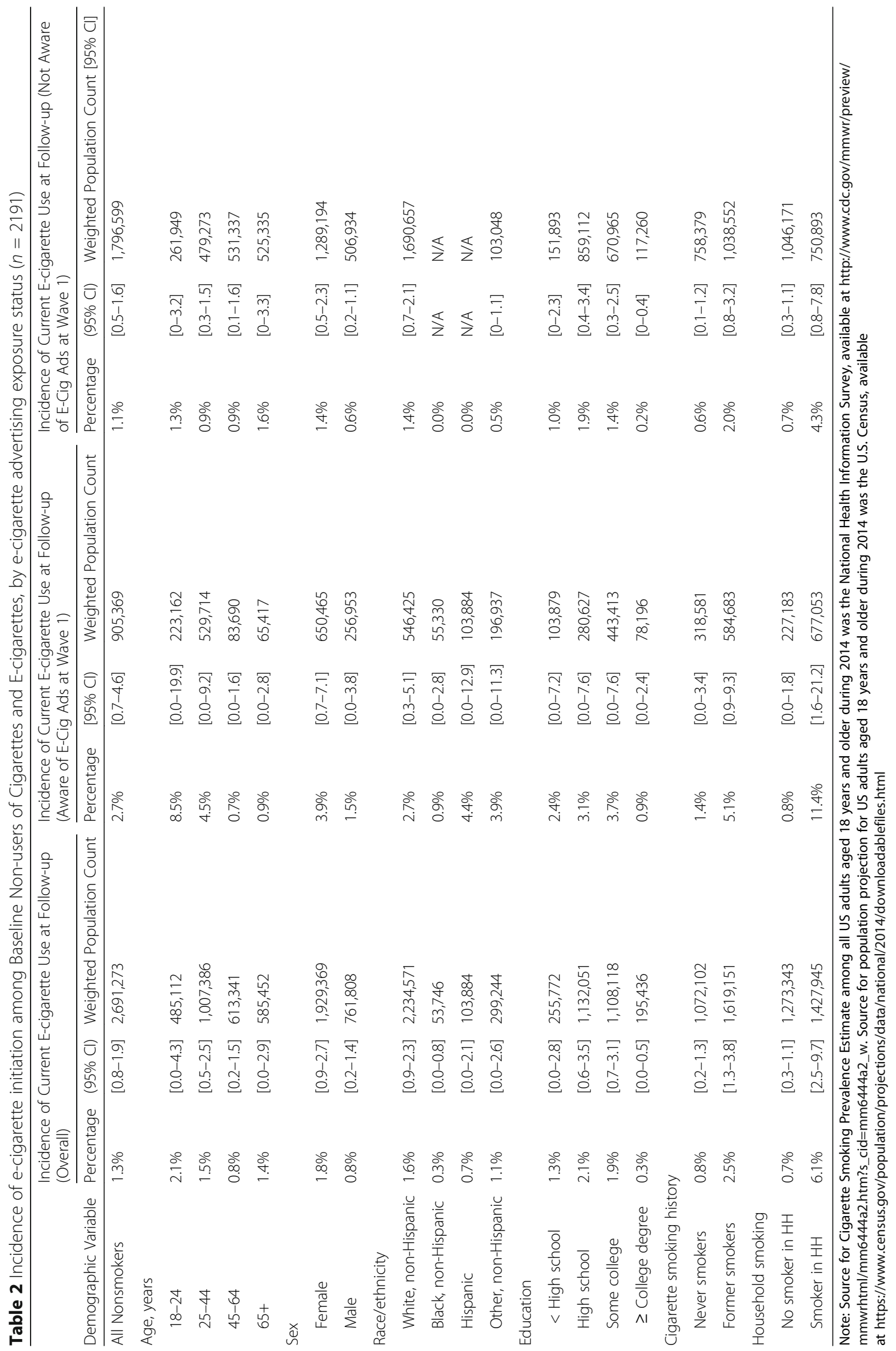


Table 3 Odds Ratios for Current E-cigarette Use ${ }^{a}$ at Follow-up among Baseline Non-users of Cigarettes and E-cigarettes

$(n=2191)$

\begin{tabular}{lll}
\hline Characteristic & $\mathrm{aOR}$ & $95 \% \mathrm{Cl}$ \\
\hline $\begin{array}{l}\text { Receptivity to e-cigarette } \\
\text { advertisement at Baseline }\end{array}$ & $1.57^{*}$ & {$[1.04,2.37]$} \\
$\begin{array}{l}\text { Aware of Tips advertisement } \\
\text { at Baseline }\end{array}$ & 0.61 & {$[0.23,1.57]$} \\
$\begin{array}{l}\text { Gender (reference: female) } \\
\quad \text { Male }\end{array}$ & $0.35^{*}$ & {$[0.14,0.90]$} \\
$\begin{array}{l}\text { Age (reference: 18-24) } \\
\text { 25-44 }\end{array}$ & 0.98 & {$[0.23,4.16]$} \\
$45-64$ & 0.32 & {$[0.07,1.47]$} \\
$65+$ & 0.44 & {$[0.06,3.11]$}
\end{tabular}

Race/ethnicity (reference: white)

$\begin{array}{lll}\text { Black } & 0.20 & {[0.02,1.58]} \\ \text { Hispanic } & 0.72 & {[0.18,2.88]} \\ \text { Other } & 0.53 & {[0.09,3.13]}\end{array}$

Education (reference:

$<$ high school)

High school

Some college

$\geq$ College degree

$[0.06,1.59]$

Cigarette smoking history

(reference: never smoker)

Former smoker

Household smoking (reference: no household smoker)

Someone else in household smokes

Note: Model controls for region fixed effects

Abbreviations: AOR Adjusted odds ratio, $\mathrm{Cl}$ confidence interval, e-cigarette Electronic cigarette

${ }^{*} p<0.05$

${ }^{a}$ Current e-cigarette users at follow-up were defined as persons who reported using e-cigarettes some days or every day

${ }^{\mathrm{b}}$ Receptivity was computed as an average of six items, each item self-rated on a scale of 1 to 5 (from 1 strongly disagree, to 5 strongly agree) describing the perceived effectiveness of the advertisement shown to the respondent. The six items measured in relation to the advertisement's effectiveness were: "worth remembering"; "grabbed my attention"; "powerful"; "informative"; "meaningful" or "convincing." Responses were averaged for each ad and then across advertisements to obtain a single value for a respondents' overall receptivity of the e-cigarette advertisements

at the state, local, and tribal government levels to address e-cigarette marketing, advertising, and sponsorship activities that may appeal to non-users of any tobacco product, particularly vulnerable populations, such as youth and young adults.

We found differences among sociodemographic groups in baseline exposure and receptivity to e-cigarette advertisements; specifically, racial/ethnic minorities and persons with lower education reported higher exposure and receptivity to e-cigarette advertisements. These differences could be due, in part, to industry targeting of lower socioeconomic groups. Not all e-cigarette advertising is from major tobacco companies, but the tobacco industry comprises a large segment of the e-cigarette market share and has a history of targeting racial/ethnic minorities with conventional tobacco product promotional activities and advertisements [18, 19].

This study's major strength is the use of longitudinal data to assess the effect of receptivity to e-cigarette advertisement on e-cigarette initiation. Nonetheless, there are some limitations to this study. First, tobacco use status was self-reported and may have been subject to misreporting. Second, we were unable to measure exposure to all existing e-cigarette advertisements and may thus have underestimated prevalence of exposure to e-cigarette advertisements. Because of space constraints in the survey, each participant was only shown one advertisement selected randomly from a set of several existing advertisements. This is therefore not a measure of overall awareness to the entire spectrum of e-cigarette advertisements featured on different channels, including $\mathrm{TV}$, the internet, magazines, and other print and nonprint media. Nonetheless, even with the conservative estimation of exposure, prevalence of exposure (16.6\%) was relatively high, and significant associations between receptivity to e-cigarette advertisements at baseline and current e-cigarette use at follow-up were observed, thus emphasizing the reach and impact of e-cigarette advertisements. Fourth, the survey did not collect data on history of e-cigarette use; thus, never and former users could not be differentiated in the analysis. Finally, given the relatively low initiation rate $(1.1 \%)$, there was large variability in some point estimates, as indicated by wide confidence intervals.

\section{Conclusion}

Among adult non-users of e-cigarettes and conventional cigarettes at baseline, receptivity to e-cigarette advertisements was associated with higher odds of using e-cigarettes at follow-up. These findings underscore the importance of efforts to address e-cigarette advertising, promotion, and sponsorship activities that may lead to initiation of e-cigarette use by nonsmokers.

\section{Abbreviations}

E-cigarettes: Electronic cigarettes; OR: Odds ratios

\section{Acknowledgements}

The findings and conclusions in this report are those of the authors and do not necessarily represent the official position of the Centers for Disease Control and Prevention.

\section{Funding}

There was no external funding for this study. KD, PS, and WR are employed at RTI International. 


\section{Availability of data and materials}

Data could be made available to all interested researchers upon request to the corresponding author.

\section{Authors' contributions}

Authors IA, KD, DP, BK, SC conceived of the study. IA wrote the initial draft of the manuscript. IA, KD, PS, WR conducted the data analysis. IA, KD, DP, PS, BK, SC, WR contributed to the interpretation of the data, and review, revision and approval of the final article. All authors read and approved the final manuscript.

\section{Ethics approval and consent to participate}

All data used in this study were secondary data. The study was thus deemed as non-human subject research and IRB review was not sought or obtained (45 CFR Part 46).

\section{Consent for publication}

This study was conducted using de-identified secondary data. Hence, consent for publication does not apply.

\section{Competing interests}

The authors declare that they have no competing interests.

\section{Publisher's Note}

Springer Nature remains neutral with regard to jurisdictional claims in published maps and institutional affiliations.

\section{Author details}

${ }^{1}$ Office on Smoking and Health, National Center for Chronic Disease Prevention and Health Promotion, Centers for Disease Control and Prevention, 4770 Buford Hwy NE, Mailstop F-79, Atlanta, GA 30341, USA. ${ }^{2}$ RTI International, Atlanta, GA, USA

\section{Received: 10 April 2017 Accepted: 11 October 2017}

Published online: 06 November 2017

\section{References}

1. Kim AE, Arnold KY, Makarenko O. E-cigarette advertising expenditures in the U.S., 2011-2012. Am J Prev Med. 2014;46:409-12. https://doi.org/10.1016/j. amepre.2013.11.003.

2. Truth Initiative. Vaporized: majority of youth exposed to e-cigarette advertising. Washington, DC: Truth Initiative; 2015. http://truthinitiative.org/ research/vaporized-majority-youth-exposed-e-cigarette-advertising

3. Herzog B, Gerberi J, Scott A. Tobacco-Nielsen c-store data-e-cig \$ sales decline moderates. Wells Fargo Securities: Charlotte, NC; 2014. http://www. c-storecanada.com/attachments/article/153/Nielsen\%20C-Stores\%20\%20Tobacco.pdf

4. Herzog B, Gerberi J, Scott A. Tobacco talk: vapors/tanks driving next wave of e-vapor growth. Wells Fargo Securities: Charlotte, NC; 2014. http://www. vaporworldexpo.com/PDFs/Tobacco_Talk_Vapors_Tanks_ \%20March\%202014.pdf

5. Richardson A, Ganz O, Vallone D. Tobacco on the web: surveillance and characterisation of online tobacco and e-cigarette advertising. Tob Control. 2015;24:341-7. https://doi.org/10.1136/tobaccocontrol-2013-051246.

6. Pepper JK, Emery SL, Ribisl KM, et al. Effects of advertisements on smokers' interest in trying e-cigarettes: the roles of product comparison and visual cues. Tob Control. 2014;23(Suppl 3):iii31-6. https://doi.org/10.1136/ tobaccocontrol-2014-051718.

7. Rutten $\sqcup$, Blake $K D$, Agunwamba AA, et al. Use of e-cigarettes among current smokers: associations among reasons for use, quit intentions, and current tobacco use. Nicotine Tob Res. 2015;17:1228-34. https://doi.org/10. 1093/ntr/ntv003.

8. U.S. Preventive Services Task Force. Tobacco smoking cessation in adults and pregnant women: behavioral and pharmacotherapy interventions. 2015. http://www.uspreventiveservicestaskforce.org/Page/Document/draftrecommendation-statement147/tobacco-use-in-adults-and-pregnantwomen-counseling-and-interventions1 (Accessed 1 Mar 2016).

9. Smith DM, Bansal-Travers M, O'Connor RJ, et al. Associations between perceptions of e-cigarette advertising and interest in product trial amongst US adult smokers and non-smokers: results from an internet-based pilot survey. Tob Induc Dis. 2015;13:14. https://doi.org/10.1186/s12971-015-0039-6.
10. Farrelly MC, Duke JC, Crankshaw EC, et al. A randomized trial of the effect of e-cigarette TV advertisements on intentions to use e-cigarettes. Am J Prev Med. 2015;49:686-93. https://doi.org/10.1016/j.amepre.2015.05.010.

11. U.S. Department of Health and Human Services (USDHHS). The health consequences of smoking - 50 years of progress: a report of the Surgeon General. Atlanta, GA: U.S. Department of Health and Human Services, Centers for Disease Control and Prevention, National Center for Chronic Disease Prevention and Health Promotion, Office on Smoking and Health 2014. http:// www.cdc.gov/tobacco/data_statistics/sgr/50th-anniversary/index.htm

12. WHO Framework Convention on Tobacco Control, Conference of the Parties to the WHO Framework Convention on Tobacco Control. Electronic nicotine delivery systems, including electronic cigarettes. 2012. http://apps. who.int/gb/fctc/PDF/cop5/FCTC_COP5_13-en.pdf.

13. Davis KC, Nonnemaker JM, Farrelly MC, et al. Exploring differences in smokers' perceptions of the effectiveness of cessation media messages. Tob Control. 2011;20:26-33. https://doi.org/10.1136/tc.2009.035568.

14. Neff $L$, Patel D, Davis KC, et al. Evaluation of the national Tips From Former Smokers campaign: the 2014 longitudinal cohort. Prev Chronic Dis. 2016;13: 150556. https://doi.org/10.5888/pcd13.150556.

15. Federal Trade Commission. Federal Trade Commission cigarette report for 2013. 2016. https:/www.ftc.gov/system/files/documents/reports/federal-tradecommission-cigarette-report-2013/2013cigaretterpt.pdf (Accessed 1 May 2016).

16. Federal Trade Commission. Federal Trade Commission smokeless tobacco report for 2013. 2016. https://www.ftc.gov/system/files/documents/reports/ federal-trade-commission-smokeless-tobacco-report-2013/2013tobaccorpt. pdf (accessed 1 May 2016)

17. Federal Register. Deeming tobacco products to be subject to the Federal Food, Drug, and Cosmetic Act, as amended by the Family Smoking Prevention and Tobacco Control Act; restrictions on the sale and distribution of tobacco products and required warning statements for tobacco products. Fed Regist 2016. https:/www.federalregister.gov/articles/2016/05/10/2016-10685/ deeming-tobacco-products-to-be-subject-to-the-federal-food-drug-andcosmetic-act-as-amended-by-the (Accessed 27 May 2016).

18. Seidenberg AB, Caughey RW, Rees WW, et al. Storefront cigarette advertising differs by community demographic profile. Am J Health Promot. 2010;24: e26-31. https://doi.org/10.4278/ajhp.090618-QUAN-196.

19. Kwate NO, Lee TH. Ghettoizing outdoor advertising: disadvantage and ad panel density in black neighborhoods. J Urban Health. 2007;84:21-31. https://doi.org/10.1007/s11524-006-9127-5.

\section{Submit your next manuscript to BioMed Central and we will help you at every step:}

- We accept pre-submission inquiries

- Our selector tool helps you to find the most relevant journal

- We provide round the clock customer support

- Convenient online submission

- Thorough peer review

- Inclusion in PubMed and all major indexing services

- Maximum visibility for your research

Submit your manuscript at www.biomedcentral.com/submit
C Biomed Central 